\section{AB0891-HPR PATIENTS WITH RHEUMATIC DISEASE WHO WERE 'FEELING STRESSED' DURING THE SECOND WAVE COVID19 INFECTION}

H. Baharuddin ${ }^{1,2}$, S. L. Lim², S. S. Ch'ng ${ }^{2}$, M. Mohd Zain ${ }^{2}$, A. Rosman², H. Mohd Yusoof ${ }^{2}$, A. K. B. Authar Singh ${ }^{2}$, V. Y. Tay ${ }^{2}{ }^{1}{ }^{2}$ Universiti Teknologi MARA, Department of Internal Medicine, Sungai Buloh, Malaysia; ${ }^{2}$ Selayang Hospital, Department of Medicine, Batu Caves, Malaysia

Background: COVID-19 pandemic has been devastating not only medically but also socially and economically. Selangor, an urbanised state in Malaysia, has been severely affected by COVID19. There is concern that patients with rheumatic diseases (RD) may have higher risk of infection, with increased mortality ${ }^{1}$. Objectives: To investigate patients' characteristics which are associated with 'feeling stressed' among patients with RD during the second wave of COVID19 infection in Selangor.

Methods: This is a cross-sectional study conducted over 3 weeks during the second wave of COVID19 infection in Malaysia. Patients with RD, scheduled for rheumatology clinic appointment in a rheumatology referral centre were invited to participate in this study.

Personal and clinical data were collected by phone interview and from patients' medical records respectively. Patients were asked to grade their disease activity by giving a score from 0 (not active) to 10 (active). All patients were asked 'are you feeling stressed?' and the answer was recorded as yes or no. Reasons explored for a yes answer, included financial, social disruption, physical illness and future uncertainties. Categorical and continuous data were analysed using chi-squared test and student t-test, respectively. A $p$-value of $<0.05$ is considered statistically significant.

Results: Three hundred and sixty-one patients with various RD participated in this study. The mean age of these was 48.2 years (range between $16-80$ years). More than half $(54.3 \%)$ were Malay and other ethnicities were Chinese $(25.5 \%)$, Indian (18.2\%) and others (2\%). A quarter of patients (24.7\%) were not working (unemployed, retired and students) and a third of patients $(32.1 \%$ ) had unpaid work (mainly housewife). The other patients' characteristics are shown in Table 1.

Table 1. Characteristics of patients who were 'feeling stressed' and not 'feeling stressed' during the second wave of COVID19 infection.

\begin{tabular}{|c|c|c|c|c|c|}
\hline \multicolumn{2}{|c|}{ Patients' characteristics } & \multirow{2}{*}{$\begin{array}{l}\begin{array}{l}\text { No of } \\
\text { patients }\end{array} \\
272 \\
89\end{array}$} & \multirow{2}{*}{$\begin{array}{l}\text { Feeling stressed } \\
\text { S }(\mathrm{n}=83), \text { no of } \\
\text { patients }(\%)\end{array}$} & \multicolumn{2}{|c|}{$\begin{array}{l}\text { Not feeling stressed }(n=278) \text {, } p \text {-value } \\
\text { no of patients }(\%)\end{array}$} \\
\hline Age & $\begin{array}{l}<60 \\
\geq 60\end{array}$ & & & $\begin{array}{l}200(73.5) \\
78(87.6)\end{array}$ & 0.006 \\
\hline Gender & $\begin{array}{l}\text { Male } \\
\text { Female }\end{array}$ & $\begin{array}{l}61 \\
300\end{array}$ & $\begin{array}{l}16(26.2) \\
67(22.3)\end{array}$ & $\begin{array}{l}45(73.8) \\
233(77.7)\end{array}$ & 0.510 \\
\hline Ethnicity & $\begin{array}{l}\text { Malay } \\
\text { Others }\end{array}$ & $\begin{array}{l}196 \\
165\end{array}$ & $\begin{array}{l}38 \text { (19.4) } \\
45(27.3)\end{array}$ & $\begin{array}{l}158(80.6) \\
120(72.7)\end{array}$ & 0.076 \\
\hline $\begin{array}{l}\text { Relationship } \\
\text { status }\end{array}$ & $\begin{array}{l}\text { Married } \\
\text { Unmarried }\end{array}$ & $\begin{array}{l}275 \\
86\end{array}$ & $\begin{array}{l}59(21.5) \\
24(27.9)\end{array}$ & $\begin{array}{l}216(78.5) \\
62(72.1)\end{array}$ & 0.215 \\
\hline Education leve & $\begin{array}{l}\text { Up to } \\
\text { secondar } \\
\text { Tertiary }\end{array}$ & $\begin{array}{l}233 \\
128\end{array}$ & $48(20.6)$ & $185(79.4)$ & 0.145 \\
\hline Work status & $\begin{array}{l}\text { No work } \\
\text { Unpaid work } \\
\text { Paid work }\end{array}$ & $\begin{array}{c}89 \\
116 \\
156\end{array}$ & $\begin{array}{l}13(14.6) \\
20(17.2) \\
50(32.1)\end{array}$ & $\begin{array}{l}76(85.4) \\
96(82.8) \\
106(67.9)\end{array}$ & 0.002 \\
\hline $\begin{array}{c}\text { Rheumatic } \\
\text { disease }\end{array}$ & $\begin{array}{l}\text { SLE } \\
\text { RA }\end{array}$ & $\begin{array}{l}125 \\
150\end{array}$ & $\begin{array}{l}30(23.8) \\
3019.4)\end{array}$ & $\begin{array}{l}96(76.2) \\
125(80,6)\end{array}$ & 0.259 \\
\hline & Others & 80 & $23(28.8)$ & $57(71.3)$ & \\
\hline $\begin{array}{l}\text { Perceived dise } \\
\text { Use biologics }\end{array}$ & $\begin{array}{l}\text { ase activity } \\
\text { Yes }\end{array}$ & 25 & $\begin{array}{l}3.14(2.4) \\
7(28)\end{array}$ & $\begin{array}{l}1.87(2.1) \\
18(72)\end{array}$ & $\begin{array}{l}<0.001 \\
0.537\end{array}$ \\
\hline & No & 336 & 76 (22.6) & $260(77.4)$ & \\
\hline
\end{tabular}

Eighty-three (23\%) admitted to 'feeling stressed' and the stressors identified were physical illness in $34(40.9 \%)$, social disruption in $23(27.7 \%)$, financial problems in $23(27.7 \%)$ and future uncertainties in $19(22.9 \%)$. Patients' characteristics that were significantly different between patients who were 'feeling stressed' and not 'feeling stressed' were age, employment status and perceived disease activity (Table 1).

Conclusion: The COVID19 pandemic has caused mental distress in a significant number of RD patients and associations were found with older age, having paid work and perceived disease activity. Issues that may influence patients' responses, including access to rheumatology care, medication and fear of getting infection were not explored in this study.

REFERENCES

[1] Williamson EJ, et al. Factors associated with COVID-19-related death using OpenSAFELY. Nature, 2020; 584: 430-436.

Disclosure of Interests: None declared

DOI: 10.1136/annrheumdis-2021-eular.2244

\section{AB0892-HPR PATIENT PERSPECTIVES ON PROVIDER PRACTICES LEADING TO AN AXIAL SPONDYLOARTHRITIS DIAGNOSIS: A QUALITATIVE STUDY}

K. Lapane ${ }^{1}$, C. Dubé ${ }^{1}$, K. Ferrucci ${ }^{2,3}$, S. Khan4, K. A. Kuhn ${ }^{5}$, A. Ogdie ${ }^{6}$, E. Yi ${ }^{7}$, J. Kay ${ }^{8,9}$, S. H. Liu ${ }^{8,10}$. ${ }^{1}$ University of Massachusetts Medical School, Population and Quantitative Health Sciences, Worcester, United States of America; ${ }^{2}$ University of Massachusetts Medical School, Population and Quantitative Health Sciences, Worcester, United States of America; ${ }^{3}$ University of Massachusetts Medical School, Clinical and Population Health Research Program, Graduate School of Biomedical Sciences, Worcester, United States of America; ${ }^{2}$ University of Massachusetts Medical School, Population and Quantitative Health Sciences, Worcester, United States of America; ${ }^{5}$ University of Colorado School of Medicine, Division of Rheumatology, Department of Medicine, Denver, United States of America; ${ }^{6}$ Hospital of the University of Pennsylvania, Medicine, Philadelphia, United States of America; ${ }^{7}$ Novartis Pharmaceuticals Corporation, HE\&OR and Medical Access, East Hanover, United States of America; ${ }^{8}$ University of Massachusetts Medical School, Division of Rheumatology, Department of Medicine, Worcester, United States of America; ${ }^{9}$ UMass Memorial Medical Center, Rheumatology Center, Worcester, United States of America; ${ }^{10}$ University of Massachusetts Medical School, Population and Quantitative Health Sciences, Worcester, United States of America

Background: People with Axial Spondyloarthritis (axSpA) experience a diagnostic delay between 7 to 10 years. (1-5) This delay contributes to increased depression and desperation in searching for an appropriate diagnosis. (6) Consequently, people with axSpA experience impaired physical function, structural damage, and overall worsened quality of life than those who experience a timely diagnosis. (7)

Objectives: To gain knowledge and understand patients' experiences with healthcare providers in diagnosis of axSpA.

Methods: Using qualitative study design, we conducted six focus groups, with a total of 26 participants with a confirmed diagnosis of axSpA by rheumatologists from three different geographic locations: Worcester, MA, Aurora, CO and Philadelphia, PA. Focus groups were audio recorded and approximately 2 hours in duration. The focus groups were transcribed, deidentified, cleaned and stored in a secure location. NVivo software was used to code the data using a coding scheme which emerged from the focus group discussion topics. For intercode reliability, two researchers coded the data and generated summary reports for data analysis.

Results: Patients described their frustrating journeys to diagnosis and attributed the lengthy diagnosis delays to a multitude of factors. These elements include, lack of definitive diagnostic test, disease characteristics, lack of primary care providers' awareness of axSpA, time, and trust. Patients felt that their physicians dismissed their complaints or would describe their symptoms as psychosomatic. The health care system also contributed to their diagnostic delays, including the lengthy referral process to a rheumatologist and the short clinical appointments. Patients believe that to reduce diagnostic delay, physicians must work with their patients; listening and believing their patients while allotting time for patients to discuss their experiences. In addition, patients believe earlier referral to a rheumatologist, and HLA-B27 genetic testing would decrease the diagnostic delay of axSpA.

Conclusion: In this study, patients desire definitive testing in clinical practice for earlier diagnosis of axSpA. Additionally, more education regarding the guidelines to diagnose axSpA and earlier referral to rheumatologists might be needed. Until this is feasible, patients seek clinicians who will work with them until a diagnosis is made, listening, and believing their experiences and symptoms.

REFERENCES:

[1] Deodhar A, Mease P, Reveille J, Curtis J, Karunaratne P, Malhotra K. Prevalence of axial spondyloarthritis among undiagnosed chronic back pain patients in the United States [abstract]. Ann Rheum Dis. 2014;73:198-199.

[2] Deodhar A, Mease PJ, Reveille JD, et al. Frequency of Axial Spondyloarthritis Diagnosis Among Patients Seen by US Rheumatologists for Evaluation of Chronic Back Pain. Arthritis Rheumatol. 2016;68(2326-5205 (Electronic)):1669-1676.

[3] Garrido-Cumbrera M, Poddubnyy D, Gossec L, et al. The European Map of Axial Spondyloarthritis: Capturing the Patient Perspective-an Analysis of 2846 Patients Across 13 Countries. Curr Rheumatol Rep. 2019;21(15346307 (Electronic)): 19

[4] Redeker I, Callhoff J, Hoffmann F, et al. Determinants of diagnostic delay in axial spondyloarthritis: an analysis based on linked claims and patient-reported survey data. Rheumatology (Oxford) 2019;58(1462-0332 (Electronic)):1634-1638.

[5] Strand V, Singh JA. Evaluation and Management of the Patient With Suspected Inflammatory Spine Disease. Mayo Clin Proc 2017;92(1942-5546 (Electronic)):555-564. 